\section{(6) OPEN ACCESS}

\title{
Anaemia may add information to standardised disease activity assessment to predict radiographic damage in rheumatoid arthritis: a prospective cohort study
}

\author{
Burkhard Möller, ${ }_{1}^{1}$ Almut Scherer, ${ }^{2}$ Frauke Förger, ${ }^{1}$ Peter M Villiger, ${ }^{1}$ Axel Finckh, ${ }^{3}$ \\ on behalf of the Swiss Clinical Quality Management Program for Rheumatic Diseases
}

\begin{abstract}
Handling editor Tore K Kvien
- Additional material is published online only. To view please visit the journal online (http://dx.doi.org/10.1136/ annrheumdis-2012-202709).

1 Department of Rheumatology, Clinical Immunology and Allergology, University Hospital Bern, Bern, Switzerland ${ }^{2} \mathrm{SCQM}$ Office Zurich, Zurich, Switzerland

${ }^{3}$ Division of Rheumatology, University Hospital Geneva, Geneva, Switzerland
\end{abstract}

\section{Correspondence to} Dr Burkhard Möller, Department for Rheumatology, Clinical Immunology and Allergology, Bern University Hospital, Freiburgstraße, Bern 3010, Switzerland: burkhard.moeller@insel.ch

Accepted 24 February 2013 Published Online First 16 March 2013

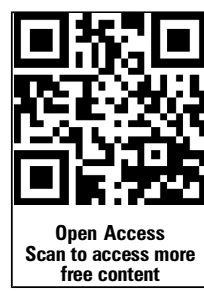

\footnotetext{
To cite: Möller $B_{\text {, }}$ Scherer $A$, Förger $F$, et al. Ann Rheum Dis 2014;73:691-696.
}

\section{ABSTRACT}

Objective Anaemia in rheumatoid arthritis (RA) is prototypical of the chronic disease type and is often neglected in clinical practice. We studied anaemia in relation to disease activity, medications and radiographic progression.

Methods Data were collected between 1996 and 2007 over a mean follow-up of 2.2 years. Anaemia was defined according to WHO (o haemoglobin $<12 \mathrm{~g} / \mathrm{dl}$, o: haemoglobin $<13 \mathrm{~g} / \mathrm{dl}$ ), or alternative criteria. Anaemia prevalence was studied in relation to disease parameters and pharmacological therapy. Radiographic progression was analysed in 9731 radiograph sets from 2681 patients in crude longitudinal regression models and after adjusting for potential confounding factors, including the clinical disease activity score with the 28joint count for tender and swollen joints and erythrocyte sedimentation rate (DAS28ESR) or the clinical disease activity index (CDAl), synthetic antirheumatic drugs and antitumour necrosis factor (TNF) therapy.

Results Anaemia prevalence decreased from more than $24 \%$ in years before 2001 to $15 \%$ in 2007. Erosions progressed significantly faster in patients with anaemia $(p<0.001)$. Adjusted models showed these effects independently of clinical disease activity and other indicators of disease severity. Radiographic damage progression rates were increasing with severity of anaemia, suggesting a 'dose-response effect'. The effect of anaemia on damage progression was maintained in subgroups of patients treated with TNF blockade or corticosteroids, and without non-selective nonsteroidal anti-inflammatory drugs (NSAIDs).

Conclusions Anaemia in RA appears to capture disease processes that remain unmeasured by established disease activity measures in patients with or without TNF blockade, and may help to identify patients with more rapid erosive disease.

\section{INTRODUCTION}

Anaemia in rheumatoid arthritis (RA) is prototypical of anaemia of chronic disease (ACD), characterised by low serum iron concentrations in conjunction with normal or increased storage iron. ${ }^{1}$ ACD without functional iron deficiency is normochromic, normocytic, and usually mild. ${ }^{2}$ Haemoglobin concentrations were a component of earlier RA disease activity measures until they were omitted during validation of the original RA disease activity score
(DAS) due to low correlation with other disease activity measures, despite moderate correlation with radiographic outcome. ${ }^{3}$

The significantly higher need for joint replacements and higher mortality rates in the anaemic patients of the British early RA cohort (ERAS) challenged the concept of causal ACD treatment by aiming at remission only with synthetic diseasemodifying antirheumatic drugs (DMARDs). ${ }^{4}$ Inhibition of human erythroid colony-forming units in the bone marrow downstream of tumour necrosis factor- $\alpha(\text { TNF- } \alpha)^{5}$ and anemia ${ }^{6}$ is reversible upon TNF- $\alpha$ blockade, even in otherwise refractory RA patients. Here, we question whether anaemia in RA is still relevant in terms of prevalence and clinical consequences in the era of TNF- $\alpha$ blockade, one of the most efficacious and common biological RA treatments.

\section{METHODS}

\section{Patients and setting}

This longitudinal population-based cohort study is nested within the Swiss clinical quality management (SCQM) database, which is described elsewhere. Patient registration in SCQM is restricted to boardcertified rheumatologists to follow the effectiveness and safety of antirheumatic therapies. More than two-thirds of all practicing rheumatologists in Switzerland contributed patients, representing $\sim 10 \%$ of all hypothetical Swiss RA patients. ${ }^{8}{ }^{9}$ Approximately $60 \%$ of patients come from private practices, 20\% from university hospitals, and 20\% from non-academic centres. Ethical approval for patient enrolment into the SCQM programme and related studies was obtained from the Swiss Academy of Medical Sciences review board. Written informed consent was provided by all 4377 participants with classification criteria-guided RA diagnosis, ${ }^{10}$ and at least one haemoglobin assessment between the start of the registry in 1996 and a major system revision in 2007.

\section{Anaemia definitions}

We used the WHO definition of anaemia with lower normal haemoglobin limits of $12 \mathrm{~g} / \mathrm{dl}$ in women and $13 \mathrm{~g} / \mathrm{dl}$ in men. ${ }^{11}$ To explore the effect of anaemia severity, we used the less stringent anaemia definition proposed by Beutler et al, ${ }^{12}$ using thresholds of $12.2 \mathrm{~g} / \mathrm{dl}$ in white women and 
of $13.7 \mathrm{~g} / \mathrm{dl}$ or $13.2 \mathrm{~g} / \mathrm{dl}$ in white men aged $20-59$ years, or 60 + years, respectively, in sensitivity analyses. 'More severe anaemia' was arbitrarily defined (in the absence of official definitions) by haemoglobin levels lower than $11 \mathrm{~g} / \mathrm{dl}$ in women and $12 \mathrm{~g} / \mathrm{dl}$ in men. Haemoglobin concentrations, white blood cell counts, and platelet counts were derived from certified local laboratories.

\section{Covariates}

Registry documentation provided the American College of Rheumatology core set of disease activity measures, ${ }^{13}$ which allowed to calculate the DAS including the 28 -joint count for tender and swollen joints and erythrocyte sedimentation rate $\left(\mathrm{DAS} 28_{\mathrm{ESR}}\right)^{14}$ and the clinical disease activity index (cDAI). ${ }^{15}$ Other covariates were age and gender, rheumatoid factor (RF) status, and RA disease duration. RA therapies, including TNF- $\alpha$ blockers, methotrexate with or without folic acid supplementation, and other synthetic DMARDs, corticosteroids, cyclo-oxygenase-II selective (Coxib type) NSAIDs, nonselective NSAIDs and proton-pump inhibitors (PPI). Generic information on the presence of haematological, renal, or gastrointestinal comorbidities was also available, without detailed information.

\section{Outcome}

Radiographic evaluation of erosions was centrally performed by an independent assessor following the Ratingen score, a validated method measuring quintiles of the total joint bone surface in 38 joints in the hands and forefeet. ${ }^{16}$ Radiographic data were expressed in percent of the maximal 190-point score and changes over time reported in absolute differences. The minimal detectable change for this method is $\sim 3.3 \%$ of the maximum score. ${ }^{17}$

\section{Statistical analysis}

Descriptive statistics included the mean and SD for normally distributed variables, and the median and IQR for nonparametric continuous variables. Sporadic missing covariates were replaced by the population mean $(<5 \%)$. Between-group differences in disease characteristics from baseline to registration were compared using a Student $t$ test for normally distributed variables, the Wilcoxon rank sum test for non-normally distributed continuous variables, and Pearson's $\chi^{2}$ test for dichotomous variables. We examined potential time trends in the prevalence and incidence of anaemia and the haemoglobin normalisation rates with Cox regression analyses. Patients were defined as 'anaemic' according to the chosen definition between two radiographs by subnormal haemoglobin concentrations in more than $50 \%$ of determinations. We used mixed-model random-slope regression for longitudinal data to analyse radiographic damage progression over time. Unless otherwise stated, data were adjusted for all baseline covariates (table 1) and the baseline and time-varying DAS2 $8_{\text {ESR }}$ or cDAI. ${ }^{14}{ }^{15}$ Patients may have switched between the anaemic and non-anaemic groups according to their time-dependent haemoglobin concentration. We chose the best-fitting parsimonious covariance structure using a series of likelihood ratio tests based on restricted maximum likelihood estimates. We examined whether time best fit the data as a linear trend or as a quadratic function. Finally, we selected the best-fitting mean response model of the outcome, controlling for other covariates for the respective outcome. All statistical tests were two-sided performed with Stata V.12 for Windows (Stata Statistical Software, StataCorp, Texas, USA), and were evaluated at the 0.05 significance level.

\section{Subgroup analyses}

Subgroups were analysed in order to further address potential treatment effects. Here, we performed statistical models for the radiographic outcome after having selected either patients with

Table 1 Baseline patient characteristics ( $n=4377$ ) according to anaemia status at inclusion

\begin{tabular}{|c|c|c|c|}
\hline Item & Anaemic $(n=1054)$ & Non-anaemic $(n=3323)$ & p Value \\
\hline Age in years & $55( \pm 15)$ & $54( \pm 12)$ & 0.08 \\
\hline Male gender (\%) & 21 & 23 & 0.17 \\
\hline DAS28 $8_{\text {ESR }}$ & $5.2( \pm 1.5)$ & $4.2( \pm 1.4)$ & $<0.001$ \\
\hline cDAl & $28.2( \pm 14.2)$ & $21.2( \pm 16.3)$ & $<0.001$ \\
\hline Disease duration in years & $6.7(6.7)$ & $6.0(6.4)$ & $<0.001$ \\
\hline Erosion score (\% of max) & $5(1.5-24)$ & $3(0.5-9)$ & $<0.001$ \\
\hline Haemoglobin (g/dl) & $11.1 \pm 1.1$ & $13.6 \pm 1.7$ & $<0.001$ \\
\hline RF positivity (\%) & 80 & 76 & 0.03 \\
\hline Subcutaneous nodules (\%) & 31 & 28 & 0.009 \\
\hline Vasculitis (\%) & 6 & 4 & 0.005 \\
\hline Methotrexate (\%) & 41 & 45 & 0.03 \\
\hline Other synthetic DMARDs (\%) & 43 & 41 & 0.36 \\
\hline Anti-TNF- $\alpha$ agents (\%) & 5 & 6 & 0.26 \\
\hline Corticosteroids (\%) & 32 & 30 & 0.22 \\
\hline Non-selective NSAIDs (\%) & 34 & 30 & 0.004 \\
\hline Coxibs (\%) & 19 & 16 & 0.03 \\
\hline Haematological comorbidities (\%) & 19 & 4 & $<0.001$ \\
\hline Renal comorbidities (\%) & 2 & 2 & 0.27 \\
\hline Gastrointestinal comorbidities (\%) & 9 & 8 & 0.38 \\
\hline
\end{tabular}


anti-TNF-therapy $(\mathrm{n}=1020$ patients $)$ or without NSAIDs $(n=1477)$, which resulted in an overlap of 520 patients for both analyses. Additional subgroup analyses were run in 1424 patients with and in 1257 subjects without corticosteroid therapy, and in 1115 patients with successful therapy as indicated by DAS $28_{\mathrm{ESR}}$ defined remission at final observation.

\section{RESULTS}

Baseline characteristics of all included patients are listed in table 1. More than $80 \%$ of subsequent consultations were scheduled after approval of TNF- $\alpha$ blocking agents in Switzerland for patients after failure of at least one conventional DMARD. Anti-TNF- $\alpha$ and other DMARD therapies were often intensified after inclusion, and the prevalence of TNF- $\alpha$ inhibitors and second-line biologics progressively reached 35\% and $2 \%$ of patients, respectively. Use of methotrexate or other conventional DMARDs was registered at least once in $64 \%$ and $60 \%$ of the patients, respectively, over time.

\section{Haemoglobin concentrations}

Patients had a mean of 4.4 haemoglobin assessments over a mean follow-up period of 2.8 years. The mean baseline haemoglobin concentration was $12.7(\mathrm{SD} \pm 1.4 \mathrm{~g} / \mathrm{dl})$ in women and $14.0 \pm 1.6 \mathrm{~g} / \mathrm{dl}$ in men. Haemoglobin levels increased by 0.08 $\pm 0.04 \mathrm{~g} / \mathrm{dl}(\mathrm{p}=0.04)$ after the first year, by $0.14 \pm 0.07 \mathrm{~g} / \mathrm{dl}$ $(p=0.06)$ after the second year, and by $0.16 \pm 0.09 \mathrm{~g} / \mathrm{dl}$ $(p=0.077)$ after the third year. Individual haemoglobin fluctuations in either direction (mean $1.6 \pm 1.2 \mathrm{~g} / \mathrm{dl}$ ) were more substantial. Higher haemoglobin concentrations were significantly associated with higher haemoglobin concentrations at baseline $(0.04,95 \%$ CI 0.03 to $0.05, \mathrm{p}<0.001)$ and male gender $(1.11$, $95 \%$ CI 1.03 to $1.19, \mathrm{p}<0.001)$, but negatively associated with higher DAS $28_{\mathrm{ESR}}(-0.20 \mathrm{~g} / \mathrm{dl}, 95 \%$ CI -0.23 to -0.18 , $\mathrm{p}<0.001)$, higher erosion scores $(-0.005,95 \%$ CI -0.007 to $-0.003, \mathrm{p}<0.001)$, and treatment with non-selective NSAIDs $(-0.16,95 \%$ CI -0.20 to $-0.12, \mathrm{p}<0.001)$, with or without PPI cotherapy. Haemoglobin levels were not associated with baseline renal or gastrointestinal comorbidity.

\section{Prevalence of anaemia}

Anemia ${ }^{11}$ occurred with similar frequency in men and women, oscillating around $24 \%$, before a continuous negative time trend started in 2001 to reach $14.7 \%$ in 2007 . No anaemia at any visit was found in $69.2 \%$ of patients, and persistent anaemia at all visits occurred in $10 \%$ of patients.

\section{Incidence and correction of anaemia}

The annual anaemia incidence rate was $7.6 \%$ in 2531 initially non-anaemic patients. Patients with higher baseline DAS28 $8_{\text {ESR }}$ (HR 1.14, 95\% CI 1.07 to $1.22, \mathrm{p}<0.001$ ), RF positivity (HR 1.49 , 95\% CI 1.16 to $1.92, \mathrm{p}=0.002)$, registered haematological comorbidity (HR 1.76, 95\% CI 1.23 to $2.53, \mathrm{p}=0.002$ ) or corticosteroid therapy (HR 1.31, 95\% CI 1.03 to 1.67, $\mathrm{p}=0.028$ ) became significantly more often anaemic. PPI comedication was often used in incident anaemia (HR 2.63, 95\% CI 0.97 to $7.14, p=0.057)$ among patients with non-selective NSAID therapy (HR $1.29,95 \%$ CI 1.06 to $1.57, \mathrm{p}=0.013$ ). By contrast, coxibs, gastrointestinal comorbidities or renal comorbidities were not associated with different anaemia incidence. Gastrointestinal toxicities were attributed to NSAIDs in 12 cases, but only one clinically manifest bleeding was reported. Haemoglobin concentrations normalised after a median of 1.3 (IQR: $0.9-3.2$ ) years in 800 initially anaemic patients. ${ }^{11}$ Anaemia correction was slower in patients with reported haematological disorder (HR $0.60,95 \%$ CI 0.48 to 0.75 , $\mathrm{p}<0.001$ ) or under non-selective NSAIDs (HR 0.73 , 95\% CI 0.60 to $0.89, \mathrm{p}=0.002)$, but was accelerated after anti-TNF- $\alpha$ (HR 1.22 , 95\% CI 1.02 to $1.45, \mathrm{p}=0.028$ ) or PPI therapy (HR $7.77,95 \%$ CI 1.86 to $32.39, \mathrm{p}=0.005)$.

\section{Reporting of anaemia and haematological comorbidities}

Treating rheumatologists reported baseline haematological comorbidity in only $19 \%$ of anaemic patients. Indicators of bone marrow insufficiency or other relevant blood cell abnormalities (white blood cell count below $3 \mathrm{~g} / \mathrm{l}$ and thrombocytopenia below $50 \mathrm{~g} / 1$ were reported in less than $0.4 \%$ or less than $0.2 \%$ of all cases, respectively. Reactive elevations in these blood cell counts, platelets $\geq 400 \mathrm{~g} / \mathrm{l}(3.6 \%)$, or leukocytes $\geq 10 \mathrm{~g} / \mathrm{l}$ $(13.8 \%)$ were more frequent. Patient's treatment with iron, vitamin $\mathrm{B}_{12}$, or erythropoietin was reported in nine, 15 and 14 cases, respectively. Malignancies were reported in $1.3 \%$ of all patients.

\section{Anaemia and erosions}

This relationship was studied in 9731 sets of radiographs from hands and forefeet in 2681 patients, of whom 627 individuals were anaemic at baseline according to WHO definition. The less stringent anaemia definition ${ }^{12}$ was fulfilled in 1487 individuals, and 506 patients complied with the definition of 'more severe anaemia'. In crude analyses and after statistical adjustments for potential confounding baseline parameters and the timedependent DAS28 $8_{\mathrm{ESR}}$ or cDAI, anaemic patients experienced significantly faster radiographic progression $(p<0.001)$ than their non-anaemic counterparts, irrespective of the employed anaemia definition (figure 1). A 'dose-response effect' was suggested by the average $2.0 \%$ annual damage progression of the maximal score in WHO-defined anaemic patients versus $1.2 \%$ in non-anaemic patients; these values were $1.4 \%$ vs $1.1 \%$ according to the higher threshold of normal haemoglobin concentrations, ${ }^{12}$ but $2.4 \%$ vs $1.2 \%$ according to the definition of 'more severe anaemia'. Significant baseline determinants of radiographic progression in all these statistical models were baseline erosion scores (mean $\sim 1.0$ in all models, $\mathrm{p}<0.001$ ), gender to the advantage of the male (mean $0.3-0.4 \%$, dependent on the model, $\mathrm{p}=0.024-0.038)$, methotrexate therapy (mean $0.2-0.3 \% \mathrm{p}=0.012-0.043$ ), and non-selective NSAID therapy (mean $\sim 0.3 \%$ in all models, $\mathrm{p}=0.013-0.024$ ).

\section{Subgroup analyses}

We obtained similar results as in the total patient population after exclusion of patients with non-selective NSAID therapy (figure 2A,B). Anaemia effects on erosive progression were reproduced in another independently selected patient population with anti-TNF therapy (figure 2C,D). By contrast with mild anaemia, ${ }^{12}$ WHO defined ${ }^{11}$ and 'more severe anaemia' exhibited similarly significant effects on $\mathrm{x}$-ray progression $(\mathrm{p}<0.001)$ in these subgroups. Anaemia effects on radiographic outcome went insignificant after exclusion of all patients with steroid registration, but remained significant in the complementary population $(\mathrm{p}<0.001$, data not shown). Finally, mean joint damage progression was faster in anaemia after selection of patients with DAS28 $8_{\mathrm{ESR}}$ defined remission at their last observation $(p=0.026$, data not shown).

\section{DISCUSSION}

In this study, WHO-defined anaemia was present in approximately every fifth patient at baseline, and at least in every third patient over their observation time, demonstrating ongoing 
A Radiographic progression and anaemia
WHO anaemia definition [11], adjustments include DAS28
ESR

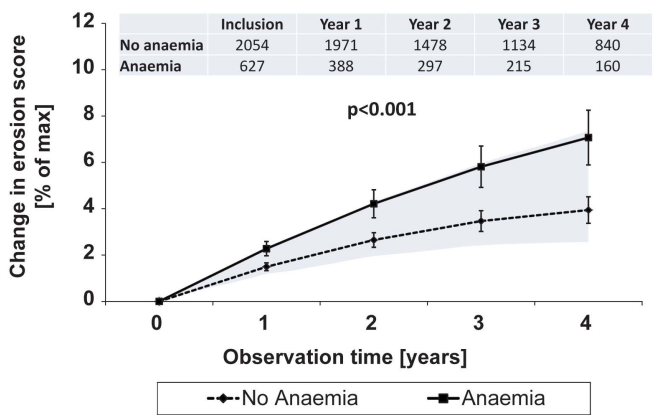

C Radiographic progression and anaemia Alternative anaemia definition [12], adjustments include DAS28 $8_{\text {ESR }}$

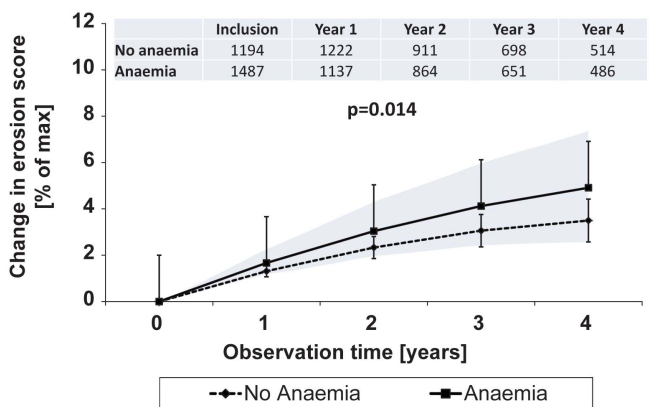

B

Radiographic progression and anaemia

WHO anaemia definition [11], adjustments include cDAI

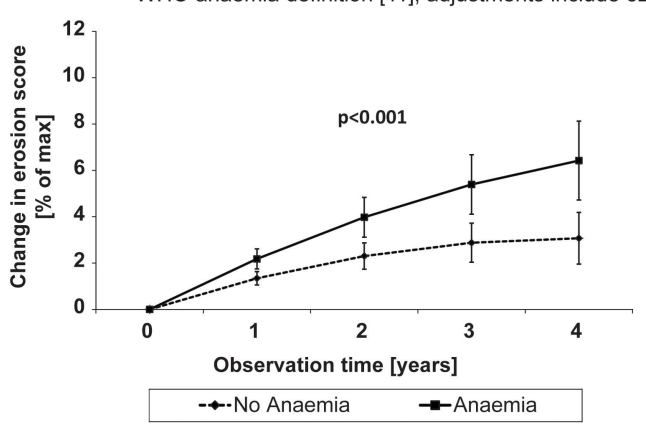

D Radiographic progression and anaemia

Alternative anaemia definition [12], adjustments include cDAl

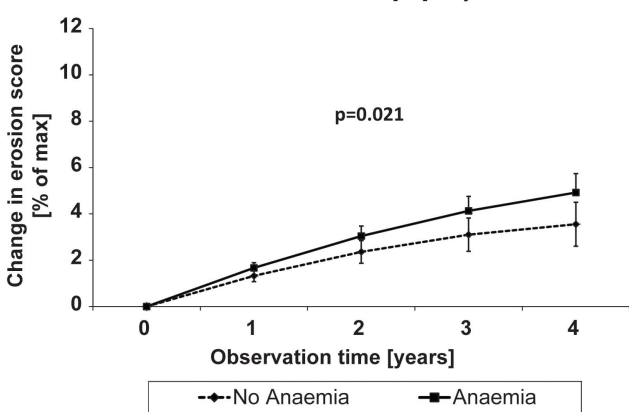

Figure 1 Erosive progression over time in all 2681 evaluable rheumatoid arthritis (RA) patients. Progression trajectories were adjusted for differences in patient characteristics at their first $x$-ray (table 1), (A,C) DAS including the 28-joint count for tender and swollen joints and erythrocyte sedimentation rate $\left(\mathrm{DAS2} \mathrm{E}_{\mathrm{ESR}}\right)$ or $(\mathrm{B}, \mathrm{D})$ clinical disease activity index where indicated, plus anti-inflammatory therapies and covariates of RA severity. Values are mean and $95 \% \mathrm{Cl}$. Erosion scores progressed significantly faster in patients with anaemia than in non-anaemic RA patients. The kinetics of damage progression accelerated with the grade of anaemia severity. (A and C) For comparison, the lower margin of the shaded area represents mean damage progression in clinical remission (DAS28 ESR $\left._{2}<2.6\right)$, and the upper margin disease progression in patients with high clinical disease activity $\left(D A S 28_{E S R}>5.1\right)$. Patient numbers at given time points are the same in left $(A, C)$ and right hand figures $(B, D)$.
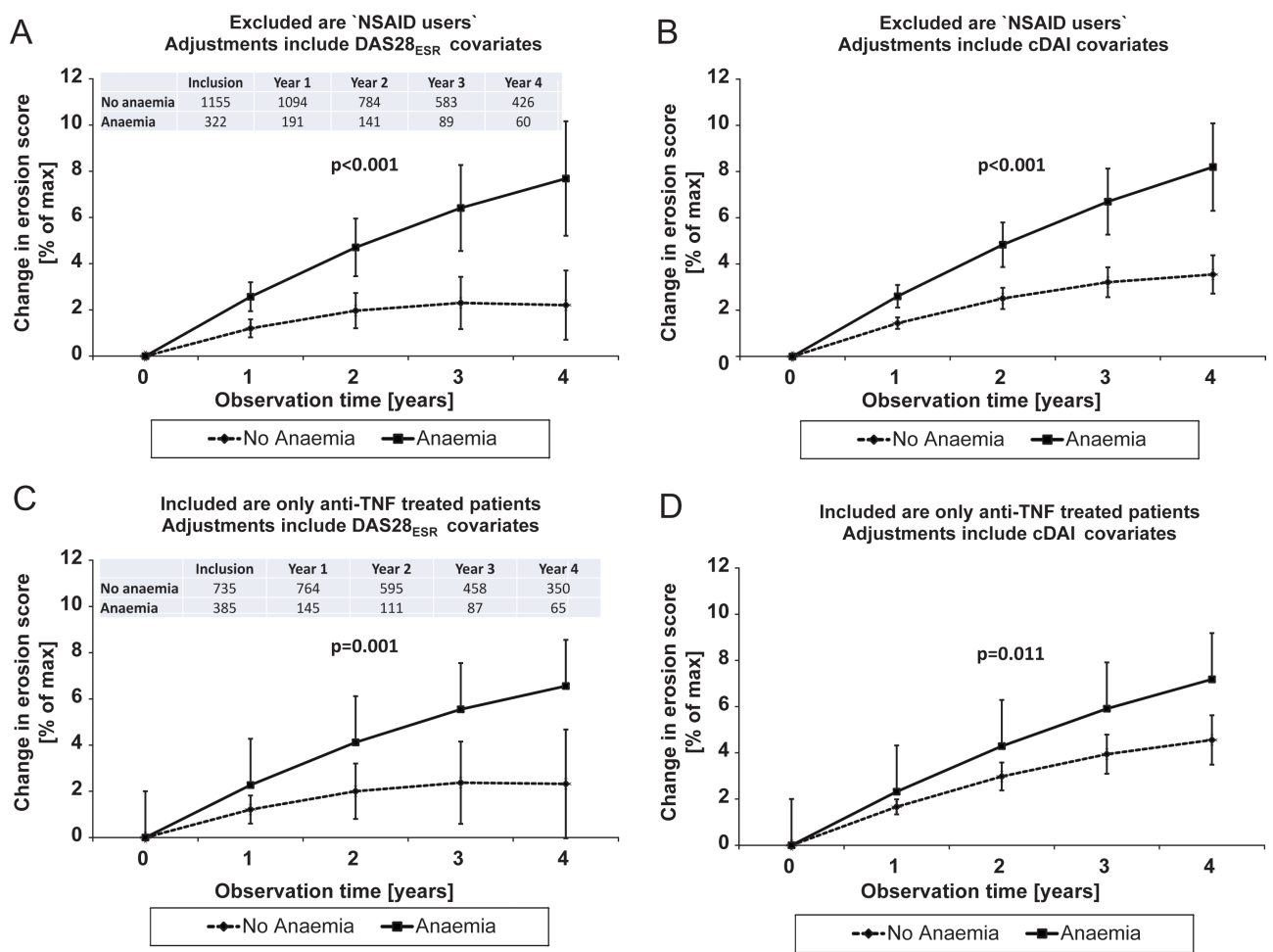

Figure 2 Erosive progression over time was analysed in patients with and without anaemia, ${ }^{11}(A, B)$ without NSAID and (C,D) with antitumour necrosis factor- $\alpha$ therapy. Values are mean and $95 \% \mathrm{Cl}$. The progression of erosions (mean $\pm 95 \% \mathrm{Cl}$ ) was adjusted for potential confounders (figure 1 , table 1). Patient numbers at given time points are the same in left $(A, C)$ and right hand figures $(B, D)$. 
relevance of anaemia despite decreasing time trends. We confirmed that anaemia in RA is usually mild, but still only partially resolved by available therapeutics and of remarkable importance for radiographic outcome.

SCQM services a typical RA registry cohort in terms of RF status, anaemia frequency and severity, ${ }_{18} 19$ other extra-articular RA manifestations, ${ }^{20}$ comorbidities, ${ }^{21}$ DMARD and TNF- $\alpha$ blocker prescription rates. ${ }^{22} 23$ SCQM is unique among the national registries in providing centralised radiographic assessment for RA patients. The necessary compromise was the abandonment of the evaluation of joint space narrowing, but the Ratingen erosion score provides good reliability and less susceptibility to ceiling effects in advanced disease, since it uses a true ordinal rating system. ${ }^{16}$

This large real-life observational study confirmed that mean joint damage progression rates are significantly lower in clinical remission than in active disease, but this goal was achieved at the end of observation in only $30 \%$ of patients. Articular inflammation can be detected by ultrasound and MRI in the absence of clinically detectable inflammation, ${ }^{24}$ which could explain the dissociation of disease activity from radiographic outcome. ${ }^{25-27}$ In the present study, anaemia-related progression of joint damage was not restricted to the patients with clinically active disease. ${ }^{14}$ Thus, anaemia may be a useful surrogate for subclinical RA disease activity.

The well established relationship between inflammation and anaemia was confirmed in this study by significant associations between lower haemoglobin concentrations and higher DAS28 $8_{\text {ESR }}$ and by faster haemoglobin normalisation after TNF- $\alpha$ blockade. ACD in RA may be caused by a shortened red blood cell lifespan, pathologic iron homeostasis induced by hepcidin, and blunted response to erythropoietin. ${ }^{1}$ Interestingly, erythropoietin treatment reduced disease activity in RA patients ${ }^{28} 29$ and tissue damage in collagen-induced arthritis models. ${ }^{30}$ Our results are consistent with anaemia as an indicator of deficient antiinflammatory properties of erythropoietin. ${ }^{31}$ Hepcidin may trigger functional iron deficiency upon induction by TNF- $\alpha$, interleukin-6, and other inflammatory stimuli, ${ }^{1}$ resulting in reduced intestinal iron uptake at the mucosal barrier, and iron retention in the reticulo-endothelial system via internalisation of the same exclusive cellular iron exporter ferroportin on both cell types. While elevated hepcidin levels could likewise be controlled by TNF- $\alpha$ blockade and manifest iron deficiency, ${ }^{32}$ its plasma concentrations appear not to be predictive for RA joint damage. ${ }^{33}$

The association between anaemia and erosions was not observed in a smaller patient population, ${ }^{34}$ but in the large ERAS inception cohort, anaemic patients underwent a more aggressive course of joint destruction. ${ }^{2}{ }^{4}$ The SCQM-RA cohort includes patients with early and established disease, with lower mean disease activity at inclusion than the ERAS cohort, and a substantial proportion of patients received anti-TNF- $\alpha$ therapy, yet the consequences of anaemia on RA outcome appear to be similar in these two populations. ${ }^{3}$

The present study is limited by missing biological markers of iron deficient erythropoiesis, such as erythrocyte indices or parameters of iron metabolism. Iron-deficiency anaemia is increasing in industrialised countries with age and with risk factors for bleeding, ${ }^{35}$ as seen here with an increased prevalence and delayed recovery of anaemia in patients taking non-selective NSAIDs, in contrast with Coxib-type NSAIDs. ${ }^{36}$ One can estimate, on the basis of prevalence data in young Swiss males, ${ }^{15}$ that iron deficiency contributes to anaemia prevalence in about $30 \%$ of the cases before, and in 50\% after, market introduction of TNF blockers. With this assumption, the prevalence of deficient erythropoiesis may still be underestimated, as iron deficiency was rapidly uncovered by erythropoietin stimulation in the vast majority of patients with longstanding and treatment-resistant active RA. ${ }^{28}$ Here, it appears necessary to point out that a higher proportion of similar cases with established disease, no matter of being clinically active on a very short term, but with subsequent functional iron deficiency on a longer time perspective would not be a confounding factor, but support the prognostic value of anaemia assessment.

Observational studies have inherent limitations, such as incomplete data, bias by indication and confounding factors. We do not believe there is a specific selection bias by anaemia in this register, and the most important confounding factors have been measured and could be adjusted for in the analysis. Corticosteroids may carry an increased risk of anaemia due to toxic mucosal drug effects ${ }^{37}$ or a bias by indication. As increased rates in radiographic damage in association with anaemia were not seen in patients without corticosteroids, this constellation differs from that in NSAID-treated patients. Divergent reporting of haematological conditions and true anaemic haemoglobin levels were explainable by the mild degree in an explained context. Missing adjustments for C-reactive protein concentrations appear less critical with regard to the superior validity of composite scores over single items. ${ }^{3}{ }^{14}$ We were unable to adjust for anticyclic citrullinated peptide antibody status as this information was missing in $40 \%$ of patients, ${ }^{38} 39$ nor do not know the shared epitope status in this large cohort, which may control immune responses ${ }^{4041}$ and determine haematopoietic progenitor cell senescence. ${ }^{42} 43$

In summary, these results indicate that anaemia may serve as predictor of worse outcome in RA patients. Our data suggest that anaemia and erosion progression are associated independently of common disease activity outcome measures. This report may add clinical background to recent discoveries at the nexus of inflammation, haematopoiesis, and iron metabolism, ${ }^{30} 31$ and highlights the clinical implications of anaemia in RA. Diagnosis of anaemia in RA should prompt a thorough search for subclinical disease activity, after exclusion of other frequent causes.

Acknowledgements We are grateful to the rheumatologists (listed under http:/l www.scqm.ch/institutions) and patients who participated in SCQM, thereby making this study possible. We are grateful to Dr Hans Schwarz, head of SCQM from 2004 to 2011, for his ongoing successful and generous efforts, and to Doris Wisler for her valuable contributions to this project. The manuscript was revised in grammar and style by San Francisco Edit writing agency.

Contributors BM planned this study, performed statistical analyses and is responsible for the overall content as guarantor. AS tested the results in alternative statistical models. FF provided important intellectual content to this study. PV provided administrative support. AF gave advice and supervised all statistical procedures. All authors approved the final manuscript. Physicians and institutions who contributed patients to the SCQM registry without fulfilling the requirements for authorship are listed under (http://www.scqm.ch/institutions).

Funding This study on SCQM data required no study-specific funding. The SCQM Foundation has received grants from the Swiss Health authorities (BAG), the Swiss Academy for Medical Sciences (SAMW), the JL Warnery Foundation, and the Swiss Society of polyarthritis patients (SPV). The pharmaceutical companies Abbott, Merck (formerly Essex Switzerland), Pfizer (formerly Wyeth Switzerland), Roche,

Bristol-Myers Squibb, Mepha, Novartis and Sanofi-Aventis are patrons of SCQM. SCQM patrons and sponsors had no role in study design, data collection, data analysis, data interpretation, writing of this manuscript, or the decision to submit this manuscript.

\section{Competing interests None.}

Ethics approval Swiss Academy of Medical Sciences review board.

Provenance and peer review Not commissioned; externally peer reviewed.

Open Access This is an Open Access article distributed in accordance with the Creative Commons Attribution Non Commercial (CC BY-NC 3.0) license, which permits others to distribute, remix, adapt, build upon this work non-commercially, 
and license their derivative works on different terms, provided the original work is properly cited and the use is non-commercial. See: http://creativecommons.org/ licenses/by-nc/3.0/

\section{REFERENCES}

1 Weiss G, Goodnough LT. Anemia of chronic disease. N Engl J Med 2005:352:1011-23.

2 Wilson A, Yu HT, Goodnough LT, et al. Prevalence and outcomes of anemia in rheumatoid arthritis: a systematic review of the literature. Am J Med 2004; 116(Suppl 1):S50-S57.

3 van der Heijde DM, van't Hof MA, van Riel PL, et al. Validity of single variables and composite indices for measuring disease activity in rheumatoid arthritis. Ann Rheum Dis 1992; 51:177-81.

4 Young A, Koduri G. Extra-articular manifestations and complications of rheumatoid arthritis. Best Pract Res Clin Rheumatol 2007;21:907-27.

5 Means RT Jr, Dessypris EN, Krantz SB. Inhibition of human colony-forming-unit erythroid by tumor necrosis factor requires accessory cells. J Clin Invest 1990;86:538-41.

6 Doyle MK, Rahman MU, Han C, et al. Treatment with infliximab plus methotrexate improves anemia in patients with rheumatoid arthritis independent of improvement in other clinical outcome measures-a pooled analysis from three large, multicenter, double-blind, randomized clinical trials. Semin Arthritis Rheum 2009;39:123-31.

7 Uitz E, Fransen J, Langenegger $\mathrm{T}$, et al. Clinical quality management in rheumatoid arthritis: putting theory into practice. Swiss Clinical Quality Management in Rheumatoid Arthritis. Rheumatology (Oxford) 2000;39:542-9.

8 Myasoedova E, Crowson CS, Kremers HM, et al. Is the incidence of rheumatoid arthritis rising?: results from Olmsted County, Minnesota, 1955-2007. Arthritis Rheum 2010:62:1576-82

9 Neovius M, Simard JF, Askling J. Nationwide prevalence of rheumatoid arthritis and penetration of disease-modifying drugs in Sweden. Ann Rheum Dis 2011;70:624-9.

10 Arnett FC, Edworthy SM, Bloch DA, et al. The American Rheumatism Association 1987 revised criteria for the classification of rheumatoid arthritis. Arthritis Rheum 1988;31:315-24

11 DeMaeyer E, Adiels-Tegman M. The prevalence of anaemia in the world. World Health Stat Q 1985;38:302-16.

12 Beutler $E$, Waalen J. The definition of anemia: what is the lower limit of normal of the blood hemoglobin concentration? Blood 2006;107:1747-50.

13 Felson DT, Anderson JJ, Boers $\mathrm{M}$, et al. The American College of Rheumatology preliminary core set of disease activity measures for rheumatoid arthritis clinical trials. The Committee on Outcome Measures in Rheumatoid Arthritis Clinical Trials. Arthritis Rheum 1993:36:729-40.

14 Prevoo ML, van't Hof MA, Kuper $\mathrm{HH}$, et al. Modified disease activity scores that include twenty-eight-joint counts. Development and validation in a prospective longitudinal study of patients with rheumatoid arthritis. Arthritis Rheum 1995;38:44-8

15 Aletaha D, Smolen J. The Simplified Disease Activity Index (SDAI) and the Clinical Disease Activity Index (CDAI): a review of their usefulness and validity in rheumatoid arthritis. Clin Exp Rheumatol 2005:23:S100-8.

16 Rau R, Wassenberg $\mathrm{S}$, Herborn $\mathrm{G}$, et al. A new method of scoring radiographic change in rheumatoid arthritis. J Rheumatol 1998:25:2094-107.

17 Finckh A, Moller B, Dudler J, et al. Evolution of radiographic joint damage in rituximab-treated versus TNF-treated rheumatoid arthritis cases with inadequate response to TNF antagonists. Ann Rheum Dis 2012;71:1680-5.

18 Wolfe F, Michaud K. Anemia and renal function in patients with rheumatoid arthritis. J Rheumatol 2006;33:1516-22.

19 Han C, Zhao N, Rahman MU, et al. A case-control study of anaemia in patients with rheumatoid arthritis treated with disease-modifying antirheumatic drugs in an adult population in the US: prevalence and impact on healthcare utilisation. J Med Econ 2008:11:255-64.

20 Turesson C, O'Fallon WM, Crowson CS, et al. Occurrence of extraarticular disease manifestations is associated with excess mortality in a community based cohort of patients with rheumatoid arthritis. I Rheumatol 2002;29:62-7.

21 Hyrich K, Symmons D, Watson K, et al. Baseline comorbidity levels in biologic and standard DMARD treated patients with rheumatoid arthritis: results from a national patient register. Ann Rheum Dis 2006;65:895-8.
22 Ziegler S, Huscher D, Karberg K, et al. Trends in treatment and outcomes of rheumatoid arthritis in Germany 1997-2007: results from the National Database of the German Collaborative Arthritis Centres. Ann Rheum Dis 2011:69:1803-8.

23 Furst $D E$, Pangan AL, Harrold LR, et al. Greater likelihood of remission in rheumatoid arthritis patients treated earlier in the disease course: results from the Consortium of Rheumatology Researchers of North America registry. Arthritis Care Res (Hoboken) 2011;63:856-64.

24 Brown AK, Conaghan PG, Karim Z, et al. An explanation for the apparent dissociation between clinical remission and continued structural deterioration in rheumatoid arthritis. Arthritis Rheum 2008:58:2958-67.

25 Mulherin D, Fitzgerald O, Bresnihan B. Clinical improvement and radiological deterioration in rheumatoid arthritis: evidence that the pathogenesis of synovial inflammation and articular erosion may differ. Br J Rheumatol 1996;35:1263-8.

26 Molenaar ET, Voskuyl AE, Dinant $\mathrm{HJ}$, et al. Progression of radiologic damage in patients with rheumatoid arthritis in clinical remission. Arthritis Rheum 2004:50:36-42.

27 Smolen JS, Han C, van der Heijde DM, et al. Radiographic changes in rheumatoid arthritis patients attaining different disease activity states with methotrexate monotherapy and infliximab plus methotrexate: the impacts of remission and tumour necrosis factor blockade. Ann Rheum Dis 2009;68:823-7.

28 Kaltwasser JP, Kessler U, Gottschalk R, et al. Effect of recombinant human erythropoietin and intravenous iron on anemia and disease activity in rheumatoid arthritis. J Rheumatol 2001;28:2430-6.

29 Peeters HR, Jongen-Lavrencic M, Vreugdenhil G, et al. Effect of recombinant human erythropoietin on anaemia and disease activity in patients with rheumatoid arthritis and anaemia of chronic disease: a randomised placebo controlled double blind 52 weeks clinical trial. Ann Rheum Dis 1996:55:739-44.

30 Cuzzocrea S, Mazzon E, di Paola R, et al. Erythropoietin reduces the degree of arthritis caused by type II collagen in the mouse. Arthritis Rheum 2005;52:940-50.

31 Nairz M, Schroll A, Moschen AR, et al. Erythropoietin contrastingly affects bacterial infection and experimental colitis by inhibiting nuclear factor-kappaB-inducible immune pathways. Immunity 2011:34:61-74.

32 van Santen S, van Dongen-Lases EC, de Vegt F, et al. Hepcidin and hemoglobin content parameters in the diagnosis of iron deficiency in rheumatoid arthritis patients with anemia. Arthritis Rheum 2011;63:3672-80.

33 Sellam J, Kotti S, Fellahi $\mathrm{S}$, et al. Serum hepcidin level is not an independent surrogate biomarker of disease activity or of radiographic progression in rheumatoid arthritis: results from the ESPOIR cohort. Ann Rheum Dis 2013:72:312-14.

34 Nikolaisen C, Figenschau Y, Nossent JC. Anemia in early rheumatoid arthritis is associated with interleukin 6-mediated bone marrow suppression, but has no effect on disease course or mortality. J Rheumatol 2008:35:380-6.

35 Pang WW, Schrier SL. Anemia in the elderly. Curr Opin Hematol 2012;19:133-40.

36 Chan FK, Lanas A, Scheiman J, et al. Celecoxib versus omeprazole and diclofenac in patients with osteoarthritis and rheumatoid arthritis (CONDOR): a randomised trial. Lancet 2010:376:173-9.

37 Laine L. Approaches to nonsteroidal anti-inflammatory drug use in the high-risk patient. Gastroenterology 2001;120:594-606.

38 van der Woude D, Syversen SW, van der Voort El, et al. The ACPA isotype profile reflects long-term radiographic progression in rheumatoid arthritis. Ann Rheum Dis 2010;69:1110-16.

39 Scherer HU, van der Woude D, Willemze A, et al. Distinct ACPA fine specificities, formed under the influence of HLA shared epitope alleles, have no effect on radiographic joint damage in rheumatoid arthritis. Ann Rheum Dis 2011;70:1461-4.

40 de Vries-Bouwstra JK, Goekoop-Ruiterman YP, Verpoort KN, et al. Progression of joint damage in early rheumatoid arthritis: association with HLA-DRB1, rheumatoid factor, and anti-citrullinated protein antibodies in relation to different treatment strategies. Arthritis Rheum 2008:58:1293-8.

41 Gourraud PA, Boyer JF, Barnetche T, et al. A new classification of HLA-DRB1 alleles differentiates predisposing and protective alleles for rheumatoid arthritis structural severity. Arthritis Rheum 2006;54:593-9.

42 Schonland SO, Lopez C, Widmann T, et al. Premature telomeric loss in rheumatoid arthritis is genetically determined and involves both myeloid and lymphoid cell lineages. Proc Natl Acad Sci USA 2003;100:13471-6.

43 Colmegna I, Diaz-Borjon A, Fujii $\mathrm{H}$, et al. Defective proliferative capacity and accelerated telomeric loss of hematopoietic progenitor cells in rheumatoid arthritis. Arthritis Rheum 2008:58:990-1000. 